Marquette University

e-Publications@Marquette

Psychology Faculty Research and Publications

Psychology, Department of

6-1-2016

Brief Report: Assessment of Intervention Effects on In Vivo Peer Interactions in Adolescents with Autism Spectrum Disorder (ASD)

Bridget Dolan

Marquette University, bridget.dolan@marquette.edu

Amy V. Van Hecke

Marquette University, amy.vanhecke@marquette.edu

Audrey M. Carson

Marquette University, audreymcarson@gmail.com

Jeffrey S. Karst

Marquette University, jeffrey.karst@marquette.edu

Sheryl Jayne Stevens

Marquette University, sheryl.stevens@marquette.edu

See next page for additional authors

Accepted version. Journal of Autism and Developmental Disorders, Vol. 46, No. 6 (June 2016):

2251-2259. DOI. (C) 2016 Springer. Used with permission.

The final publication is available at Springer via http://dx.doi.org/10.1007/s10803-016-2738-0. 
Authors

Bridget Dolan, Amy V. Van Hecke, Audrey M. Carson, Jeffrey S. Karst, Sheryl Jayne Stevens, Kirsten A.

Schohl, Stephanie Potts, jenna Kahne, Nina Linneman, Rheanna Remmel, and E. Hummel 


\title{
Brief Report: Assessment of Intervention Effects on in Vivo Peer Interactions in Adolescents with Autism Spectrum Disorder (ASD)
}

\author{
Bridget K. Dolan \\ Department of Psychology, Marquette University \\ Milwaukee, WI \\ Amy V. Van Hecke \\ Department of Psychology, Marquette University \\ Milwaukee, WI \\ Audrey M. Carson \\ Department of Psychology, Marquette University \\ Milwaukee, WI \\ Texas Children's Hospital, Houston, TX \\ Jeffrey S. Karst \\ Department of Psychology, Marquette University \\ Children's Hospital of Wisconsin \\ Milwaukee, WI \\ Sheryl Stevens \\ Department of Psychology, Marquette University \\ Milwaukee, WI \\ Kirsten A. Schohl
}

Journal of Autism and Developmental Disorders, Vol. 46, No. 6 (June 2016): pg. 2251-2259. DOI. This article is @ Springer and permission has been granted for this version to appear in e-Publications@Marquette. Springer does not grant permission for this article to be further copied/distributed or hosted elsewhere without the express permission from Springer. 
NOT THE PUBLISHED VERSION; this is the author's final, peer-reviewed manuscript. The published version may be accessed by following the link in the citation at the bottom of the page.

\author{
Department of Psychology, Marquette University \\ Milwaukee, WI \\ Stephanie Potts \\ Department of Psychology, Marquette University \\ Milwaukee, WI \\ Jenna Kahne \\ Department of Psychology, Marquette University \\ Milwaukee, WI \\ Nina Linneman \\ Department of Psychology, Marquette University \\ Milwaukee, WI \\ R. Remmel \\ Department of Psychology, Marquette University \\ Milwaukee, WI \\ University of Alabama, Tuscaloosa, AL \\ E. Hummel \\ Department of Psychology, Marquette University \\ Milwaukee, WI
}

\begin{abstract}
This study aimed to evaluate the effectiveness of a randomized controlled trial of a social skills intervention, the Program for the Education and Enrichment of Relational Skills (PEERS: Laugeson et al. in J Autism Dev Disord 39(4): 596-606, 2009), by coding digitally recorded social interactions between adolescent participants with ASD and a typically developing adolescent confederate. Adolescent participants engaged in a 10-min peer interaction at pre- and post-treatment. Interactions were coded using the Contextual Assessment of Social Skills (Ratto et al. in J Autism Dev Disord 41(9): 1277-1286, 2010). Participants who completed PEERS demonstrated significantly improved vocal expressiveness, as well as a trend toward improved overall quality of rapport, whereas participants in the waitlist group exhibited worse performance on these domains. The degree of this change was related to knowledge gained in PEERS.
\end{abstract}

Keywords: Autism ASD Adolescence PEERS Intervention Social skills Observational In vivo Friendships 
NOT THE PUBLISHED VERSION; this is the author's final, peer-reviewed manuscript. The published version may be accessed by following the link in the citation at the bottom of the page.

\section{Introduction}

Social interaction deficits serve as a hallmark feature of Autism Spectrum Disorder (ASD; Wang and Spillane 2009), and these social skill challenges do not remit with age (White et al. 2007). For this population, adolescence is particularly challenging because friendships and social connections become increasingly important during this period (Mitchell et al. 2010). Not surprisingly, deficits in social skills among individuals with ASD lead to isolation and lack of friendships. The latter is concerning given the high rates of comorbid depression and withdrawal that exist within the ASD population in adulthood (Stewart et al. 2006), which may worsen with social isolation.

Numerous intervention studies have sought to examine the efficacy of programs designed to ameliorate social skill impairments in adolescents with ASD (see Kaat and Lecavalier 2014; Schreiber 2011 for reviews). One social skills intervention, the Program for the Education and Enrichment of Relational Skills (PEERS: Laugeson et al. 2009) for Adolescents, targets relationship development in order to remediate social isolation in adolescents with ASD. The developers of PEERS found that the treatment group increased in their knowledge of social skills, hosted and attended more get-togethers, and improved social skills immediately following the intervention per parent-report (Laugeson et al. 2009), and they also found that these gains maintained at long-term follow-up 1-5 years post-intervention (Mandelberg et al. 2014). A research group independent from the developers replicated the pilot study's initial findings, further supporting the program's efficacy (Schohl et al. 2013). PEERS also has received cross-cultural validation with a Korean sample (Yoo et al. 2014), and these findings mirror that of both the initial study (Laugeson et al. 2009) and the replication (Schohl et al. 2013) in that the Korean adolescents with ASD demonstrated significant improvements in knowledge of PEERS concepts and interpersonal skills, as well as a decrease in symptoms related to ASD and depressive symptoms, as per parent- and adolescent-report measures. In a study investigating neural plasticity immediately following PEERS, Van Hecke et al. (2013) found that adolescents who completed the program demonstrated greater left hemisphere asymmetry in the gamma frequency band, as assessed via electroencephalogram (EEG) 
at follow-up, compared to a waitlist control group who exhibited right hemisphere dominance. The shift to left EEG asymmetry is supportive of a positive affective style and being approach oriented in social interaction, whereas right EEG asymmetry relates to withdrawn behavior (Van Hecke et al. 2013). These neural changes noted in the experimental group also related to behavioral outcomes in terms of increased social knowledge, greater social contact (e.g., more gettogethers), and fewer autism-related symptoms, as per adolescentand parent-report (Van Hecke et al. 2013). PEERS is arguably the most extensively researched and empirically validated social skills intervention for adolescents with high-functioning ASD (Reichow et al. 2013). Overall, previous investigations of PEERS have relied on adolescent- and parent-report to assess social knowledge and skill improvement.

Examining social skills via an observational method reduces potential bias introduced in parent-report, as well as the poor or inaccurate reporting that often accompanies adolescent self-report (Mazefsky et al. 2011). Observation of in vivo social skills provides a level of ecological validity not afforded in self- and other-report measures. To date, there are no known published studies that have assessed the effectiveness of PEERS for Adolescents via an observational method. While many coding schemes exist for young children (e.g., Early Social Communication Scales: ESCS; Mundy et al. 2003), these are inappropriate to assess adolescents' social behavior, as interactions shift from being play-based in childhood to demanding greater conversational reciprocity in adolescence. Other coding schemes to assess child and adolescent peer interactions, such as the Social Interaction Observation System (SIOS; Bauminger 2002), are typically utilized in a naturalistic setting (e.g., during break time; for example, see Lerner and Mikami 2012). While a naturalistic setting presents a clear advantage of obtaining a sample of adolescents' social functioning in their daily life (e.g., lunch), the challenge of controlling for potential confounds across participants poses a limitation. Laboratory-based observations allow for greater control and similarity across participants' interactions. One published rating system designed to assess conversational skills for adolescents and adults in a laboratory-based setting is the Contextual Assessment of Social Skills (CASS: Ratto et al. 2010), which assesses adolescents' social functioning in live interactions. The creators of PEERS for Adolescents 
have adapted the program for use with young adults (Gantman et al. 2012), and an independent research site examined change in social skills via the CASS on a small sample of adult participants (White et al. 2015). Compared to pre-treatment ratings, one participant asked more questions, two young adults initiated more topic changes, and four young adults demonstrated improvement in conversational involvement (White et al. 2015).

\section{Aims and Hypotheses}

The current study sought to examine the effectiveness of PEERS (Laugeson et al. 2009) for improving social skills among adolescents with ASD, utilizing an in vivo social interaction paradigm with a typically developing adolescent. The central aim of this study examined whether in vivo social skills of adolescents with ASD improved following completion of the PEERS program, as compared to a waitlist comparison group, in a randomized controlled trial (RCT). The CASS paradigm (Ratto et al. 2010) was used to code the live interactions. The secondary aim of this study was to examine whether adolescents in PEERS gained knowledge of concepts related to how to make and maintain friends, and if this knowledge correlated with improvements on in vivo social skills on the CASS.

\section{Methods}

\section{Participants}

Participants in this study represent a subset of a larger sample (i.e., had available pre- and post-test digitally recorded interactions; see Schohl et al. 2013) and consisted of 58 participants with ASD, ranging in age from 11 to 16 years old. Adolescents with ASD were recruited from local intervention agencies, autism support groups, and an in-house waiting list for PEERS. Prior to the first appointment, families of adolescents with ASD were randomly assigned to either the Experimental (EXP; $n=28$ ) or Waitlist Control (WL; $n=30$ ) group. EXP families completed the intake appointment, entered PEERS immediately, and then completed a follow-up appointment immediately after concluding the 14-week treatment. WL families completed the first appointment, did not enter PEERS, completed a 
follow-up appointment approximately 14 weeks later, and were enrolled in the program 3-4 months later. Adolescents with ASD met a variety of criteria to be eligible for participation in the study, including ASD and IQ screening tests (see Schohl et al. 2013).

The 11-16 year old typically developing (i.e., no diagnosis of a developmental disorder) adolescent confederates for the social interactions were recruited by advertising the opportunity to participate in the present study at various locations on a university campus. Four confederates assisted with this study: two males (Latino and Caucasian, respectively) and two females (Latina and Caucasian, respectively), ranging in age from 12 to 15 years old. Adolescent confederates and their parents provided assent and consent, respectively, before interacting with the adolescents with ASD. The typically developing confederates received a \$10 Target gift card for each peer interaction he or she completed.

\section{Procedure}

Written consent and assent was obtained prior to beginning the intake appointment. If the adolescent with ASD met inclusion criteria during the intake, adolescents with ASD and their caregivers completed a variety of self-report measures on social, emotional, and adaptive functioning. Then, at that same appointment, adolescents with ASD and their caregivers were escorted to the laboratory for completion of a physiological assessment.

Each adolescent with ASD and caregiver returned to the laboratory for a separate appointment consisting of a 10-min peer interaction with an unfamiliar, gender-matched, typically developing adolescent. Prior to beginning the interaction, the adolescent confederate was instructed to act friendly and naturally with the adolescent with ASD, to convey interest in what the adolescent with ASD said, and to follow the participant's lead in the conversation. These instructions were given to elicit the most natural and noncontrived interaction as possible. During the consent procedure, the adolescents with ASD were told that they would be interacting with a same-age peer for $10 \mathrm{~min}$ as part of the study. When the participants with ASD arrived for their peer interaction appointment, they were reminded that they would "hang out" with a peer similar in age. During 
this second appointment, participants were escorted to a small, private room where the typically developing adolescent confederate was seated at a table. The adolescent with ASD was directed to sit across from the typically developing confederate. The graduate research assistant introduced the adolescent with ASD to the typically developing confederate and said that the two adolescents could play Jenga, work on a puzzle, and/or chat and hang out for $10 \mathrm{~min}$. A Sony HDRCX330 HD Flash Memory Camcorder (9.2 megapixels) was mounted on a tripod and placed perpendicular and approximately five feet away from the table to record the interactions. The graduate research assistant pressed the record button on the video camera, exited the room, and returned after $10 \mathrm{~min}$. This procedure was repeated at post-test with a different, unfamiliar, typically developing adolescent confederate.

\section{Measures}

\section{The Contextual Assessment of Social Skills (CASS: Ratto et al. 2010)}

The CASS is a social functioning assessment that was designed primarily for use with adolescents and young adults with highfunctioning ASD (Ratto et al. 2010). While the CASS consists of nine items (two items rated using frequency counts and seven items rated on a 7-point Likert scale), only the seven Likert scale ratings were utilized in this study because it was determined that the frequency count items may conflict with specific skills taught in PEERS (e.g., the "don't be an interviewer" rule from PEERS conflicted with counting topic changes in the interaction; Laugeson and Frankel 2010, p. 72). The seven items utilized for coding assess a variety of social skills domains, including vocal expressiveness, gestures, positive affect, kinesic arousal, and social anxiety. The last two items consist of global ratings, assessing overall involvement/interest in the conversation and overall quality of rapport during the interaction. Each social skill domain is rated on a scale from 1 to 7 , and a specific qualitative description accompanies each score, which allows raters to assign a score that best describes how the adolescent with ASD performed on a particular domain (e.g., positive affect; for specific codes, see Ratto et al. 2010). According to the CASS manual, scores below a 6 indicate 
some level of social skill deficit (Ratto et al. 2010). According to the authors, the CASS has high internal consistency on all nine items (standardized alpha $=.83$; Ratto et al. 2010).

Five undergraduate coders were trained on the CASS by coding eight training videos provided by its authors (Ratto et al. 2010). The coders achieved at least $80 \%$ agreement overall with the authors' codes in order to become reliable on the CASS. Inter-rater reliability was established between the coders by double coding $25 \%$ of the current study's videos. Undergraduate coders were blind to PEERS group assignment (EXP or WL) and pre- or post-test status. The intraclass correlation (ICC) values were excellent among the raters, with values ranging from .85 to .93 for each of the seven items on the CASS. Finally, videos of the four confederates were randomly selected and double coded by the raters to assess for similarity in interaction styles among the confederates. The raters coded the confederates on the overall interest and involvement and overall quality of rapport ratings to assess their involvement and reciprocity while interacting with the adolescents with ASD. Independent sample t-tests were computed, comparing overall interest/involvement and overall quality of rapport scores between the two male confederates and two female confederates, respectively. While no differences were found between the male confederates, independent sample t-tests produced significant differences between the two female confederates on both of the CASS ratings (equal variances not assumed), $t(22.63)=3.88$, $p<.05$ (overall interest/involvement) and $t(29.09)=2.14, p<.05$ (overall quality of rapport). The female confederates were not equivalent in their interaction styles, and thus, the five females with ASD in the current study were excluded from the remainder of the analyses.

\section{Test of Adolescent Social Skills Knowledge (TASSK: Laugeson and Frankel 2006)}

The TASSK consists of 22 items in a multiple-choice format, assessing adolescents' knowledge about the specific social skills taught during PEERS. The items on the TASSK reflect content taught during each session [e.g., "The goal of a conversation is to: (1) Make the other person like you; or (2) Find common interests"]. A Total score 
reflecting knowledge of PEERS concepts was calculated. Interaction coders also were kept blind to participants' TASSK scores. Participants in both the EXP and WL groups completed the TASSK at the intake and follow-up appointments prior to their peer interaction, respectively. Given that the TASSK does not produce subscales and consists of a variety of topics, Cronbach's reliability alpha was not computed for this measure.

\section{Intervention for Adolescents with ASD: Program for the Education and Enrichment of Relational Skills (PEERS: Laugeson et al. 2009)}

PEERS is an empirically supported, manualized, outpatient treatment program designed to teach motivated adolescents with high functioning ASD the social skills needed in order to make and keep friends (Laugeson et al. 2009). PEERS meets for 14, weekly, 90-min sessions. Each session consists of a didactic lesson, targeting a particular social skill (see Table 1 ). PEERS teaches the basics of conversation before progressing to more complex social topics, such as initiating peer interaction, hosting get-togethers, and handling arguments and disagreements. The leader of the adolescent group demonstrates the highlighted skill through appropriate and/or inappropriate role-plays. Following the role-plays, the adolescents engage in a behavioral rehearsal with one another to practice these skills while the leader of the adolescent group listens and provides performance feedback. To close each session, adolescents and their parents reunite to review the upcoming homework assignment. Homework assignments accompany each session, providing adolescents with a framework for generalizing newly acquired skills to their school environment and extracurricular activities. The parent group meets concurrently in a separate room, discussing the previous week's homework assignment, and the group leader troubleshoots any problems that arose while adolescents completed the assignment. The parent group leader reviews concepts from the didactic lesson so the parents understand what their adolescent is learning, which allows parents to serve as a social coach for their adolescent (Laugeson et al. 2009).

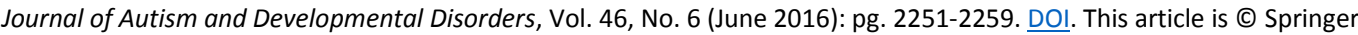
and permission has been granted for this version to appear in e-Publications@Marquette. Springer does not grant permission for this article to be further copied/distributed or hosted elsewhere without the express permission from Springer. 
NOT THE PUBLISHED VERSION; this is the author's final, peer-reviewed manuscript. The published version may be accessed by following the link in the citation at the bottom of the page.

Table 1. PEERS sessions with descriptions

\begin{tabular}{|c|c|c|}
\hline Sessi & Didactic lesson & Description of the lesson \\
\hline 1 & $\begin{array}{l}\text { Introduction and } \\
\text { conversational skills I: } \\
\text { trading information }\end{array}$ & $\begin{array}{l}\text { Trading information during conversations with peers } \\
\text { in order to find common interests }\end{array}$ \\
\hline 2 & $\begin{array}{l}\text { Conversational skills II: } \\
\text { two-way conversations }\end{array}$ & $\begin{array}{l}\text { Having two-way conversations with peers. Parents } \\
\text { identify teen activities leading to potential } \\
\text { friendships }\end{array}$ \\
\hline 3 & $\begin{array}{l}\text { Conversational skills III: } \\
\text { electronic } \\
\text { communication }\end{array}$ & $\begin{array}{l}\text { Appropriate use of voicemail, email, text } \\
\text { messaging, instant messaging, and the Internet in } \\
\text { developing pre-existing friendships. Parents taught } \\
\text { the social structure of school peer groups }\end{array}$ \\
\hline 4 & $\begin{array}{l}\text { Choosing appropriate } \\
\text { friends }\end{array}$ & $\begin{array}{l}\text { Pursuing teen extra-curricular activities leading to } \\
\text { friendships. Teens taught the social structure of } \\
\text { school peer groups and identify groups they might } \\
\text { fit in with }\end{array}$ \\
\hline 5 & $\begin{array}{l}\text { Appropriate use of } \\
\text { humor }\end{array}$ & $\begin{array}{l}\text { Appropriate use of humor in same-age peer } \\
\text { interactions. Parents taught strategies to provide } \\
\text { feedback to their teen about their use of humor }\end{array}$ \\
\hline 6 & $\begin{array}{l}\text { Peer entry I: entering a } \\
\text { conversation }\end{array}$ & Steps involved in joining conversations with peers \\
\hline 7 & $\begin{array}{l}\text { Peer entry II: exiting a } \\
\text { conversation }\end{array}$ & $\begin{array}{l}\text { How to assess receptiveness during peer entry and } \\
\text { how to gracefully exit conversations when not } \\
\text { accepted }\end{array}$ \\
\hline 8 & Get-togethers & $\begin{array}{l}\text { Planning and having successful get-togethers with } \\
\text { friends. Appropriate parent monitoring and } \\
\text { intervention during teen get-togethers }\end{array}$ \\
\hline 9 & Good sportsmanship & $\begin{array}{l}\text { The rules of good sportsmanship during games and } \\
\text { sports }\end{array}$ \\
\hline 10 & $\begin{array}{l}\text { Rejection I: teasing and } \\
\text { embarrassing feedback }\end{array}$ & $\begin{array}{l}\text { Appropriate responses to teasing. Differentiating } \\
\text { between teasing and negative feedback and using } \\
\text { appropriate responses to the latter }\end{array}$ \\
\hline 11 & $\begin{array}{l}\text { Rejection II: bullying } \\
\text { and bad reputations }\end{array}$ & $\begin{array}{l}\text { Strategies for handling bullying and changing a bad } \\
\text { reputation }\end{array}$ \\
\hline 12 & Handling disagreements & Resolving disagreements with peers \\
\hline 13 & Rumors and gossip & Strategies for handling rumors and gossip \\
\hline 14 & $\begin{array}{l}\text { Graduation and } \\
\text { termination }\end{array}$ & $\begin{array}{l}\text { on party and ceremony. Maintai } \\
\text { iendships after termination }\end{array}$ \\
\hline
\end{tabular}

Reproduced with permission of the authors

\section{Data Analytic Plan}

To assess the primary aim of examining in vivo social skill improvements as assessed via the CASS, $2 \times 2$ mixed model ANOVAs

Journal of Autism and Developmental Disorders, Vol. 46, No. 6 (June 2016): pg. 2251-2259. DOI. This article is @ Springer and permission has been granted for this version to appear in e-Publications@Marquette. Springer does not grant permission for this article to be further copied/distributed or hosted elsewhere without the express permission from Springer. 
were conducted for each of the seven domains (vocal expressiveness, gestures, positive affect, kinesic arousal, social anxiety, overall interest/involvement, and overall quality of rapport) with GROUP (EXP or WL) as the between-subjects factor and TIME (pre or post) as the within-subjects factor. An additional variable for each CASS rating was created to indicate whether participants made either: (1) negative change (a decrease in each CASS rating from pre- to post-treatment); (2) no change (CASS rating remained the same); or (3) positive change (an increase in CASS rating for pre- to post-treatment). Chi square analyses were computed with these new variables for each CASS rating, which allowed for examination of the frequency of participants who made improvements, regardless of the amount of improvement. Finally, a $2 \times 2$ mixed model ANOVA was computed to examine group differences in TASSK Total scores from pre- to posttest. Similarly, GROUP (EXP or WL) served as the between-subjects factor and TIME (pre or post) was the within-subjects factor. Change scores were calculated for the TASSK Total score and each of the seven CASS ratings (pre minus post). More negative scores indicated greater improvements on the TASSK and CASS ratings, respectively. Utilizing these change scores, a Pearson's product-moment correlation was conducted to assess if knowledge of PEERS concepts on the TASSK correlated with improvements on in vivo social skills on the CASS.

\section{Results}

All statistical analyses were conducted using SPSS 22.0 (SPSS, Inc., 2013). Exploratory data analyses were conducted to assess for normality and outliers of codes on each of the seven items on the CASS at both pre- and post-treatment. There were 10 outlier values from pre-treatment ratings, and 11 outlier values from post-treatment ratings. These data points were replaced using Winsorization, which involves the outlier value being replaced with the next closest data point (Tabachnik and Fidell 2007). The 21 corrected values represented less than $3 \%$ of the data.

There were 28 males in the EXP group and 25 males in the WL group whose interactions were coded using the CASS at pre- and posttreatment (see Table $\underline{2}$ for demographic information). Means and 
standard deviations at pre- and post-test for each of the CASS ratings for the EXP and WL groups are presented in Table $\underline{3}$. On the vocal expressiveness rating, there was a significant main effect for the within-subjects variable TIME, $F(1,51)=7.61, p<.05 ; \eta^{2}=.13$; observed power $=.77$. However, this main effect for the vocal expressiveness domain was qualified by a GROUP $\times$ TIME interaction, $F(1,51)=4.61, p<.05$; partial $\eta^{2}=.08$; observed power $=.56$. The EXP group demonstrated significant improvements in their vocal expressiveness, whereas the WL group's performance remained relatively unchanged from pre- to post-test. A statistical trend for a GROUP $x$ TIME interaction on the overall quality of rapport rating also was noted, $F(1,55)=3.85, p=.055$; partial $\eta^{2}=.07$; observed power $=.49$. Although this interaction did not reach traditional levels of significance, the EXP group exhibited improvements in overall quality of rapport while the WL group' performance decreased in this domain. There were no significant main effects or interactions for the gestures, positive affect, kinesic arousal, social anxiety, and overall involvement/interest ratings.

Table 2. Demographics and means and standard deviations for baseline variables for experimental and waitlist control groups

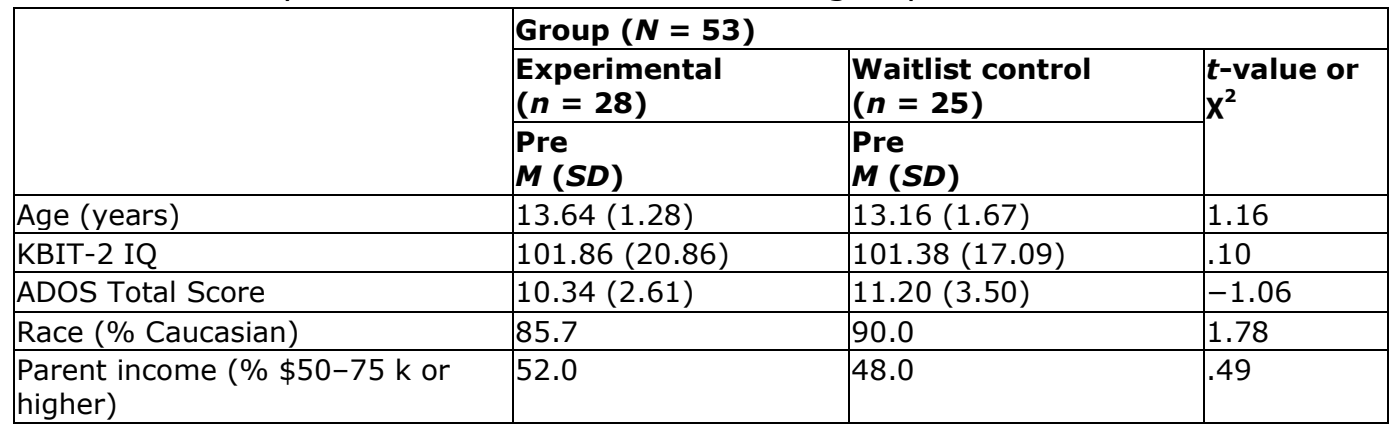

KBIT-2 Kaufman Brief Intelligence Test-Second Edition, ADOS Autism Diagnostic Observation Schedule

$* p<.05 ; * * p<.01 ; * * * p<.001$ 
Table 3. Means and standard deviations for CASS ratings and $p$-values for interactions for experimental and waitlist control groups

\begin{tabular}{|c|c|c|c|c|c|}
\hline & \multicolumn{5}{|c|}{ Group $(N=53)$} \\
\hline & \multicolumn{2}{|c|}{ Experimental $(n=28)$} & \multicolumn{2}{|c|}{ Waitlist Control $(n=25)$} & \multirow{2}{*}{$\begin{array}{l}\text { GROUP } \times \text { TIME } \\
p \text { value }\end{array}$} \\
\hline & Pre $M(S D)$ & Post $M(S D)$ & Pre $M(S D)$ & Post M(SD) & \\
\hline Vocal expressiveness & $4.54(1.03)$ & $5.18(.77)$ & $4.60(.87)$ & $4.68(1.18)$ & $.037 *$ \\
\hline Gestures & $3.54(1.71)$ & $3.71(1.61)$ & $2.96(1.81)$ & $3.08(1.63)$ & .90 \\
\hline Positive affect & $4.75(1.00)$ & $4.92(.72)$ & $4.68(.80)$ & $4.52(.96)$ & .21 \\
\hline Kinesic arousal & $5.14(1.43)$ & $5.00(1.09)$ & $4.92(1.15)$ & $4.68(1.18)$ & .82 \\
\hline Social anxiety & $4.82(1.44)$ & $5.18(.82)$ & $4.56(1.36)$ & $4.44(1.32)$ & .28 \\
\hline Overall Interest/involvement & $4.75(1.32)$ & $5.18(.77)$ & $4.72(1.06)$ & $4.68(1.34)$ & .23 \\
\hline Overall quality of rapport & $4.32(1.44)$ & $4.92(.86)$ & $4.44(1.04)$ & $4.36(1.41)$ & $.055^{\wedge}$ \\
\hline
\end{tabular}

CASS Contextual Assessment of Social Skills; lower scores on the CASS are associated with social skill impairment or deficit

$* p<.05 ; * * p<.01 ; * * * p<.001{ }^{\wedge}{ }^{\wedge}$ statistical trend

Chi square analyses were significant for overall quality of rapport, $\mathrm{X}^{2}=6.07, p<.05$, with the EXP group containing more participants ( $57.1 \% ; n=16$ ) who made positive change (i.e., an increase in overall quality of rapport from pre- to post-PEERS), as compared to only $32 \%(n=8)$ of the WL group demonstrating positive change in rapport on the CASS at follow-up. Chi square analyses on ratings of vocal expressiveness, gestures, positive affect, kinesic arousal, social anxiety, and overall involvement/interest did not reach traditional levels of significance.

To examine the secondary aim, whether knowledge of PEERS concepts changed and was related to CASS ratings, a $2 \times 2$ mixed model ANOVA was conducted. There was a significant main effect for time, $F(1,51)=172.68, p<.05$; however, this main effect was qualified by a GROUP $\times$ TIME interaction, $F(1,51)=139.6, p<.05$; partial eta squared $=.77$; observed power $=1.00$. The EXP group showed significant improvements on the TASSK at post-treatment, while the WL group did not significantly improve from pre- to posttest. Next, bivariate correlations were conducted to assess the relationship between knowledge of PEERS concepts and in vivo social skills. A Pearson's product-moment correlation indicated that improvements in TASSK Total scores were significantly related to improvements in overall quality of CASS rapport, $r(51)=.28, p<.05$. 
NOT THE PUBLISHED VERSION; this is the author's final, peer-reviewed manuscript. The published version may be accessed by following the link in the citation at the bottom of the page.

\section{Discussion}

The purpose of this study was to examine the effectiveness of a relationship development program to improve social skills in adolescents with ASD, as assessed via an observational coding system. While results did not reveal global improvements on all of the domains of the CASS, significant improvements in terms of vocal expressiveness were noted, as well as a statistical trend toward enhanced overall quality of rapport, for adolescents who received the PEERS intervention. A greater percentage of participants who completed PEERS exhibited improvements in overall quality of rapport at post-intervention. The EXP group demonstrated greater knowledge of PEERS concepts at post-treatment, and change in TASSK scores and overall quality of rapport were significantly correlated.

It is noteworthy that while the other domains of the CASS yielded non-significant differences, participants who completed PEERS demonstrated significant improvements in vocal expressiveness at post-treatment. According to the CASS manual, the vocal expressiveness rating evaluates participants' ability to appropriately vary their vocal tone to communicate ideas or emotions (Ratto et al. $\underline{2010}$, p. 4). Similarly, individuals vary vocal tone to express interest. Although varying one's vocal tone is not explicitly addressed in treatment, the initial PEERS sessions focus on conversational reciprocity while emphasizing the importance of showing interest in others' experiences, thoughts, and opinions, in order to establish and maintain friendships. This skill is often challenging for individuals with ASD, and thus, adolescents in PEERS watch role-plays that demonstrate how these skills are properly implemented (i.e., appropriate role-play of what the skill should look like) and how other people react when these social rules are violated (i.e., inappropriate role-play of not implementing the skill). It is possible that this emphasis on rules for exhibiting interest translates into appropriate variations in vocal tone following treatment. The vocal expressiveness rating also captures the rate and rhythm at which participants speak. Arguably, some of the oddities and inappropriateness in individuals' with ASD vocal tone might be due to underlying anxiety or a lack of confidence in social interaction. It is possible that EXP participants who received PEERS felt more comfortable interacting with the adolescent 
confederate following treatment. Specifically, homework assignments in PEERS are intended to promote generalization of the newly acquired skills (e.g., conversational reciprocity, initiating peer conversations, and hosting get-togethers) to adolescents' daily life outside of treatment. Through these weekly exposures, the goal is for participants to increase the number of positive peer interactions while reducing anxiety associated social engagement. The improvements in vocal expressiveness may be one indicator suggesting that adolescents who completed PEERS feel more comfortable in peer interactions, compared to the participants waiting for treatment. It also is important to acknowledge the possibility that nonspecific intervention effects (e.g., adolescents' motivation to improve their skills, group leaders' therapeutic alliance with participants, etc.) may have influenced the improvements noted in vocal expressiveness at post-treatment for the EXP group; however, it is beyond the scope of the current study to explicitly examine these factors.

A greater percentage of EXP participants demonstrated improvements in the overall quality of rapport domain. The CASS manual describes the overall quality of rapport rating as the overall smoothness of the conversation, the degree to which the adolescent with ASD established rapport and engaged in reciprocity during the interaction, and their ability to initiate and maintain the conversation (Ratto et al. 2010, p. 6). Arguably, the first two modules of the PEERS intervention, trading information and having a two-way conversation, most closely correspond to the overall quality of rapport rating. For instance, asking questions and building on conversation, which are a part of the rapport rating, closely relate to the concepts taught in the first PEERS didactic lesson of trading information (i.e., ask the other person about himself/herself and share the conversation). Similarly, in the overall quality of rapport rating, coders look for conversational reciprocity, maintenance of the conversation, and appropriate topic changes, which are all skills addressed in the rules of having a twoway conversation in the second session of PEERS (i.e., ask open-ended questions, do not be repetitive, and ask good follow-up questions). The aforementioned skills are foundational and were practiced in various contexts and homework assignments throughout the duration of PEERS. 
The positive relationship noted between greater knowledge of PEERS concepts and improvements in overall rapport demonstrates that adolescents at post-treatment have a better understanding of social skills and an improved ability to implement them more appropriately in vivo. This finding suggests PEERS not only targets knowledge base but also improves social skill implementation and performance. The other CASS ratings, such as positive affect (i.e., smiling, nodding, etc.), are not overtly addressed or taught in PEERS, but ideally result after gaining a foundation in appropriate conversation skills and experiencing success while utilizing these skills in vivo with peers and potential friends. Since all of the CASS items do not directly match with specific skills taught in PEERS, this could account for the lack of significant improvements across all domains observed in vivo even though the adolescents in PEERS demonstrated an increase in social skill knowledge. Further, it may take adolescents less time to learn concepts taught in PEERS, while it takes longer to develop and implement these skills in vivo. Nonetheless, it is encouraging that adolescents completing PEERS demonstrated a significant improvement in vocal expressiveness and a trend toward improved overall quality of rapport following treatment.

\section{Limitations of the Present Study}

There were some limitations in the current study. First, the sample was limited in size, which in turn affected power. Second, the sample included mostly Caucasian males, which makes the findings less generalizable to more diverse samples. In future studies, a larger, more diverse sample including females should be examined. Third, the laboratory environment in which the 10-min interaction took place might have elicited less natural responses, and thus, did not accurately capture the adolescents' social skill abilities at post-treatment.

Additionally, the adolescents with ASD were told to "chat and/or play Jenga" with the typically developing confederate. This may represent a limitation, as some adolescents with ASD may need more explicit instructions in order to elicit optimal participation in social exchanges (e.g., "Remember to use the skills you learned during PEERS"), yet this type of instruction is not natural and potentially biases the group receiving treatment since the comparison group is waiting to receive PEERS. Furthermore, the adolescents were only given the option of 
playing Jenga or putting together a puzzle, which also may represent a limitation. Specifically, PEERS is designed to teach motivated adolescents how to make and keep friends. Since adolescents with ASD might still struggle with feeling motivated to interact socially with peers, having a variety of activities (e.g., several games or a snack to share) may have been helpful in eliciting more social exchanges. Finally, this study was a novel use of the CASS paradigm. The CASS was originally developed and tested via a role-play condition in which the confederates acted bored or interested, and the study sought to distinguish participants with ASD versus typically developing participants (Ratto et al. 2010; White et al. 2015). Conversely, the present study did not have the confederates behave in different ways with the adolescents with ASD. This different approach to using the CASS paradigm might contribute to the measure not distinguishing differences across the other CASS domains for the ASD groups. Despite these limitations, this study possessed a strong design, consisting of a randomized controlled trial of PEERS, with coders being blind to group membership and time point of the digitally recorded in vivo interactions.

\section{Future Directions and Conclusions}

The PEERS intervention teaches adolescents the skills necessary to make and maintain a friendship. The goal of PEERS is to foster a relationship with a same-age potential friend. Given the intervention's framework, one future direction of the current study may be to observe the adolescents with ASD with a friend that they made as a consequence of PEERS and assess their social skills with that friend at post-treatment (e.g., at school during lunch). This design may serve as a better measurement of how adolescents implement and execute the skills learned in PEERS, rather than evaluating them in an unnatural, laboratory-based assessment. Interacting with a familiar peer may highlight a completely different repertoire of responses that were not observable in the present study. It also would be interesting to see if adolescents were able to generalize the skills they learned in PEERS with an unfamiliar, gender-matched, typically developing confederate, similar to the current study's paradigm, but conduct this interaction 6-12 months after treatment. In this paradigm, the adolescents with ASD would have more time to practice and cultivate 
these skills in their day-to-day lives (e.g., at school, in extracurricular activities, etc.) before being evaluated with an unfamiliar adolescent. In this paradigm, it also would be important to provide specific instructions to the adolescents with ASD to engage in a conversation prior to beginning interaction to clarify the expectation of the interaction. The latter design would allow for researchers to see if PEERS, in fact, teaches social skills that are generalizable to social interactions other than those with the purpose of seeking potential friends. This more strenuous test of the intervention would benefit from the increased time for friendship skills to develop. Finally, given that the CASS assesses broad-band social skills and may not fully capture the specific friendship development skills addressed in PEERS, an exciting avenue of future research may be to create an in vivo observational measure that assesses specific skills taught during the program.

The present study sought to examine in vivo social interactions between an adolescent with ASD and a typically developing confederate at pre- and post-treatment, comparing an experimental group to a waitlist control group. Results revealed that adolescents receiving PEERS exhibited significant improvements in vocal expressiveness and trend toward enhanced overall quality of rapport. Additionally, more participants who received PEERS demonstrated positive change in terms of overall quality of rapport, whereas a greater amount of participants in the WL group exhibited no change from pre- to post-test. The degree of this change was related to knowledge gained in the PEERS intervention. While the other domains on the CASS did not reveal significant differences between the groups, the current study adds to the minimal literature regarding social skills development in this population, and suggests interesting avenues for future research.

\section{Acknowledgments}

This research was supported by a grant from the Autism Society of Southeastern Wisconsin (ASSEW). We would like to acknowledge all of the families that participated in this study for their time and dedication to clinical research. We also wish to thank Elizabeth Laugeson, Psy.D., UCLA, for her assistance in starting the PEERS program in Wisconsin. 
NOT THE PUBLISHED VERSION; this is the author's final, peer-reviewed manuscript. The published version may be accessed by following the link in the citation at the bottom of the page.

\section{Author Contributions}

BD conceived of the study, participated in its design and coordination, collected the data, facilitated the intervention, analyzed and interpreted the data, and drafted the manuscript. AV supervised the project and helped to design the study, analyze and interpret the data, and edit the manuscript. AC, JSK, SS, KS, and SP participated in facilitating the intervention and data acquisition. JK, LN, RR, and EH coded the study data. All authors read and approved the final manuscript.

\section{References}

Bauminger, N. (2002). The facilitation of social-emotional understanding and social interaction in high-functioning children with autism: Intervention outcomes. Journal of Autism and Developmental Disorders, 32(4), 283-298.

Gantman, A., Kapp, S. K., Orenski, K., \& Laugeson, E. A. (2012). Social skills training for young adults with high-functioning autism spectrum disorders: A randomized controlled pilot study. Journal of Autism and Developmental Disorders, 42(6), 1094-1103.

Kaat, A. J., \& Lecavalier, L. (2014). Group-based social skills treatment: A methodological review. Research in Autism Spectrum Disorders, 8(1), 15-24.

Laugeson, E. A. \& Frankel, F. (2006). Test of adolescent social skills knowledge. Available from UCLA Parenting and Children's Friendship Program, 300 Medical Plaza, Los Angeles.

Laugeson, E. A., \& Frankel, F. (2010). Social skills for teenagers with developmental and autism spectrum disorders: The PEERS treatment manual. New York: Routledge.

Laugeson, E. A., Frankel, F., Mogil, C., \& Dillon, A. R. (2009). Parent-assisted social skills training to improve friendships in teens with autism spectrum disorders. Journal of Autism and Developmental Disorders, 39(4), 596-606.

Lerner, M. D., \& Mikami, A. Y. (2012). A preliminary randomized controlled trial of two social skills interventions for youth with high-functioning autism spectrum disorders. Focus on Autism and Other Developmental Disabilities, 27(3), 145-155. doi:10.1177/1088357612450613.

Mandelberg, J., Frankel, F., Cunningham, T., Gorospe, C., \& Laugeson, E. A. (2014). Long-term outcomes of parent-assisted social skills intervention for high-functioning children with autism spectrum disorders. Autism, 18(3), 255-263.

Mazefsky, C. A., Kao, J., \& Oswald, D. P. (2011). Preliminary evidence suggesting caution in the use of psychiatric self-report measures with 
adolescents with high-functioning autism spectrum disorders. Research in Autism Spectrum Disorders, 5(1), 164-174.

Mitchell, K., Regehr, K., Reaume, J., \& Feldman, M. (2010). Group social skills training for adolescents with Asperger syndrome or high functioning autism. Journal on Developmental Disabilities, 16(10), 52-63.

Mundy, P., Delgado, C., Block, J., Venezia, M., Hogan, A., \& Siebert, J. (2003). A manual for the abridged Early Social Communication Scales (ESCS). Coral Gables, FL: University of Miami.

Ratto, A. B., Turner-Brown, L., Rupp, B. M., Mesibov, G. B., \& Penn, D. L. (2010). Development of the Contextual Assessment of Social Skills (CASS): A role play measure of social skill for individuals with highfunctioning autism. Journal of Autism and Developmental Disorders, 41(9), 1277-1286.

Reichow, B., Steiner, A. M., \& Volkmar, F. (2013). Cochrane review: Social skills groups for people aged 6 to 21 with autism spectrum disorders (ASD). Evidence-Based Child Health: A Cochrane Review Journal, 8(2), 266-315.

Schohl, K. A., Van Hecke, A. V., Carson, A. M., Dolan, B., Karst, J., \& Stevens, S. (2013). A replication and extension of the PEERS intervention: Examining effects of social skills and social anxiety in adolescents with autism spectrum disorders. Journal of Autism and Developmental Disorders, 44(3), 532-545.

Schreiber, C. (2011). Social skills interventions for children with highfunctioning autism spectrum disorders. Journal of Positive Behavior Interventions, 13(1), 49-62.

Stewart, M. E., Barnard, L., Pearson, J., Hasan, R., \& O’Brien, G. (2006). Presentation of depression in autism and Asperger syndrome: $\mathrm{A}$ review. Autism, 10(1), 103-116.

Tabachnik, B., \& Fidell, L. (2007). Using multivariate statistics. Boston: Pearson Education.

Van Hecke, A. V., Stevens, S., Carson, A. M., Karst, J. S., Dolan, B., Schohl, K., et al. (2013). Measuring the plasticity of social approach: A randomized controlled trial of effects of the PEERS intervention on EEG asymmetry in adolescents with autism spectrum disorder. Journal of Autism and Developmental Disorders, 45(2), 316-335. doi:10.1007/ s10803-013-1883-y.

Wang, P., \& Spillane, A. (2009). Evidence-based social skills interventions for children with autism: A meta-analysis. Education and Training in Developmental Disabilities, 44(3), 318.

White, S. W., Keonig, K., \& Scahill, L. (2007). Social skills development in children with autism spectrum disorders: A review of the intervention research. Journal of Autism and Developmental Disorders, 37(10), 1858-1868.

Journal of Autism and Developmental Disorders, Vol. 46, No. 6 (June 2016): pg. 2251-2259. DOI. This article is @ Springer and permission has been granted for this version to appear in e-Publications@Marquette. Springer does not grant permission for this article to be further copied/distributed or hosted elsewhere without the express permission from Springer. 
NOT THE PUBLISHED VERSION; this is the author's final, peer-reviewed manuscript. The published version may be accessed by following the link in the citation at the bottom of the page.

White, S. W., Scarpa, A., Conner, C. M., Maddox, B. B., \& Bonete, S. (2015). Evaluating change in social skills in high-functioning adults with autism spectrum disorder using a laboratory-based observational measure. Focus on Autism and Other Developmental Disabilities, . doi:10.1177/ 1088357614539836.

Yoo, H., Bahn, G., Cho, I. H., Kim, E. K., Kim, J. H., Min, J. W., et al. (2014). A randomized controlled trial of the Korean version of the PEERS ${ }^{\circledR}$ parent-assisted social skills training program for teens with ASD. Autism Research, 7(1), 145-161. doi:10.1002/aur.1354. 